\title{
PART I: RESEARCH Toward a Research Agenda on Classroom Teaching
}

In this volume, we continue our custom of publishing the keynote address from our annual fall conference. This year, Harvard educator K. Patricia Cross, most familiar to us through her work on non-traditional students, proposes a non-traditional approach to teaching improvement. She suggests that by empirically investigating questions that arise from their own teaching experiences, faculty can improve their teaching and revitalize themselves as educators. Although we've titled this section "research," it really incorporates elements of reflection, conceptualization, and practice into an argument in favor of faculty-generated research on teaching.

Professor Cross's proposal implies an important role for faculty development practitioners: we can use our varied disciplinary perspectives on teaching and learning to help faculty transform their curiosity about classroom phenomena into researchable questions; and we can assist them in planning and conducting studies that will illuminate their questions. By facilitating classroom research, we become catalysts and collaborators with faculty, helping them to generate personally relevant knowledge about teaching and learning. By encouraging faculty to share what they learn with other educators, we can, as Cross suggests, increase our understanding of the specific contexts in which teaching occurs. Faculty-generated studies will create a valuable resource for academics interested in 
improving teaching while providing a necessary foundation for development of policies and programs that support teaching improvement.

Professor Cross's remarks challenge us to participate in the renewal of teaching through classroom research; To Improve the Academy offers a context for sharing work in this domain. In 1985, we published several accounts of classroom research projects and we would like to publish more in the future. We hope the article that follows will stimulate you to initiate or extend classroom research projects with faculty colleagues to improve teaching and enhance professional development, and to contribute to our understanding of teaching and learning processes. 